\title{
The large-scale impact of climate change to Mississippi flood hazard in New Orleans
}

\author{
T. L. A. Driessen ${ }^{1}$ and M. van Ledden ${ }^{2}$ \\ ${ }^{1}$ Royal HaskoningDHV, Rivers, Deltas \& Coasts, Nijmegen, the Netherlands \\ ${ }^{2}$ Royal HaskoningDHV, Rivers, Deltas \& Coasts, Rotterdam, the Netherlands \\ Correspondence to: T. L. A. Driessen (tjeerd.driessen@ @rhdhv.com) \\ Received: 1 June 2012 - Published in Drink. Water Eng. Sci. Discuss.: 5 July 2012 \\ Revised: 14 May 2013 - Accepted: 23 May 2013 - Published: 12 July 2013
}

\begin{abstract}
The objective of this paper was to describe the impact of climate change on the Mississippi River flood hazard in the New Orleans area. This city has a unique flood risk management challenge, heavily influenced by climate change, since it faces flood hazards from multiple geographical locations (e.g. Lake Pontchartrain and Mississippi River) and multiple sources (hurricane, river, rainfall). Also the low elevation and significant subsidence rate of the Greater New Orleans area poses a high risk and challenges the water management of this urban area. Its vulnerability to flooding became dramatically apparent during Hurricane Katrina in 2005 with huge economic losses and a large number of casualties.
\end{abstract}

\begin{abstract}
A SOBEK Rural 1DFLOW model was set up to simulate the general hydrodynamics. This model included the two important spillways that are operated during high flow conditions. A weighted multi-criteria calibration procedure was performed to calibrate the model for high flows. Validation for floods in 2011 indicated a reasonable performance for high flows and clearly demonstrated the influence of the spillways.

32 different scenarios were defined which included the relatively large sea level rise and the changing discharge regime that is expected due to climate change. The impact of these scenarios on the water levels near New Orleans were analysed by the hydrodynamic model. Results showed that during high flows New Orleans will not be affected by varying discharge regimes, since the presence of the spillways ensures a constant discharge through the city. In contrary, sea level rise is expected to push water levels upwards. The effect of sea level rise will be noticeable even more than $470 \mathrm{~km}$ upstream. Climate change impacts necessitate a more frequent use of the spillways and opening strategies that are based on stages.
\end{abstract}

\section{Introduction}

The Mississippi River has the third largest river basin of the world and drains $41 \%$ of the area of the United States. The flood risk of the Mississippi River imposed on urban areas, like Baton Rouge and New Orleans, became apparent during the great flood in 1927 which was the most destructive river flood in the history of the United States (Barry, 1998). The river, discharging more than $85000 \mathrm{~m}^{3} \mathrm{~s}^{-1}$, caused levee failures at numerous places, displaced over 600000 people and flooded almost $70000 \mathrm{~km}^{2}$ causing damage for $\$ 400$ million.

Looking ahead, climate change is expected to affect the river discharge due to alterations in the water cycle. Ericson et al. (2006) found that the relative vulnerability of the Mississippi delta, compared to 39 other deltas, is extreme and is demonstrated by the population potentially being displaced by current sea level trends to 2050. USGCRP (2000) showed significant increases in the heaviest precipitation events and noted that changes in streamflow follow these changes in precipitation, but are amplified by about a factor three. Additionally, climate change induced sea level rise in combination with the local subsidence of the Mississippi River Delta causes the projected local relative sea level rise in $50 \mathrm{yr}$ to range between $+0.5 \mathrm{~m}$ and $+0.9 \mathrm{~m}$ for different rates of sea level rise (USACE, 2009; NOAA, 2011). The uncertainty in these projections is large, since the local subsidence rates 
vary strongly throughout the delta. Also, river morphological changes play a role, but they were neglected in this paper. Altogether, relative sea level rise is expected to affect river stages further upstream in the future. In combination with the alterations in streamflow the future flood water levels in the Mississippi River are subject to change.

In view of future changes there are various management challenges in the Mississippi River Delta to be dealt with in order to sustain the economic benefits for society, reduce the flood risk of urban areas, such as New Orleans, and to preserve the environmental value of the wetlands. Many of these issues are interrelated which each other. As an example, the high river levees prevent the river overflowing into the historic flood plains and therefore withhold fertile river sediment being deposited in the floodplains. This sediment starvation induces coastal marsh deterioration. Since the 1930s some $4900 \mathrm{~km}^{2}$ of coastal wetlands have already disappeared in the Gulf of Mexico and this process continues at a rate of $65 \mathrm{~km}^{2}$ per year (Bourne Jr., 2004). Marsh deterioration is also enhanced by the strong subsidence in the area which increases the potential for inundation (Nicholls et al., 2007). Subsidence enables more intrusion of salty water which destructs the fresh/brackish marshlands and allows sea water to penetrate further inland. Another water management challenge is more closely related to flood hazard in City of New Orleans. The Mississippi River levees downstream of Baton Rouge, LA, do not have large floodplains to overflow when the bankfull discharge is exceeded. This results in a steep discharge-stage relation compared to a river system that has large floodplains available on the riverside of the levees. Near New Orleans a river stage of $+5.18 \mathrm{~m}$ above the North American Vertical Datum of 1988 epoch 2004.65 (NAVD88) is used as the safe water elevation. In order to prevent exceedance of this river stage near New Orleans two important spillways have been constructed further upstream: the Bonnet Carre Spillway and the Morganza Spillway (see Fig. 1). The Bonnet Carre Spillway is closest to New Orleans and consists of 350 bays that includes wooden beams. Its inlet structure is opened when the upstream discharge at Tarbert Landing exceeds ca. $35400 \mathrm{~m}^{3} \mathrm{~s}^{-1}$. The spillway is capable of discharging almost $7080 \mathrm{~m}^{3} \mathrm{~s}^{-1}$. The Morganza Spillway is opened when the upstream discharge at Red River landing exceeds $42475 \mathrm{~m}^{3} \mathrm{~s}^{-1}$ and consists of 125 gates which are able to divert a maximum flow of almost $17000 \mathrm{~m}^{3} \mathrm{~s}^{-1}$. The Morganza Spillway diverts water to the Atchafalya River basin which is located to the west of the Mississippi River, and was opened for the second time in spring 2011. The main question that is addressed in this article is how this system of levees and spillways can be adapted in view of future changes.

The objective of this paper is to address the future changes in the Mississippi River stages in the context of climate change and sea level rise. For this purpose, a hydraulic model and an overview of modelling scenarios are presented in the following section of this paper. Next, the model results are discussed in the context of Mississippi flood hazard.

\section{Methods}

\subsection{Hydrodynamic model}

An improved one-dimensional hydraulic model was set up to describe the general hydrodynamics of the river and to simulate stages for the lower reach of the Mississippi River, which includes the cities Baton Rouge and New Orleans. This included a model of the last $492 \mathrm{~km}$ of the river before it enters the Gulf of Mexico (see Fig. 1). This model was subsequently used to perform a sensitivity analysis on the response of the river stage to climate change.

A HEC-RAS geometry was used that was provided by the Hydraulics and Hydrologic Branch of the U.S. Army Corps of Engineers (USACE) New Orleans District containing survey data obtained in 2002 and 2003. This geometry was imported in the SOBEK Rural Advanced Version 2.11.002c software (Deltares, 2010) and provided 164 crosssections between the upstream boundary at Tarbert Landing and the downstream boundary at Venice (see Fig. 1). The modelled reach receives little lateral inflow due to precipitation which justifies the use of the hydrodynamic 1DFLOW module within SOBEK Rural and the exclusion of a rainfallrunoff module.

Daily discharge at Tarbert Landing was used for setting the upstream boundary condition for unsteady flow computations. A stage-discharge relation was used to compute the daily discharge based on observed daily stages. A fixed water level, representing the yearly averaged stage, was applied at the downstream boundary condition at Venice, since no hourly data was available to incorporate the tidal signal. Although the tidal signal may have a pronounced effect on the stages in the Mississippi River during low discharges, a fixed boundary was justified, since the study focused on high flows wherein tidal influence on river stages was negligible. Storm surges on the other hand can have a considerable effect. However, the study focused on peak flows of the Mississippi River, which occur mostly during the first six months of the year. Storm surges are related to hurricanes that mostly occur from June to November. Hence, the effect of storm surges was not within the scope of this study.

\subsection{Calibration}

Calibration of the model was performed by a weighted multicriteria procedure for the main channel friction (Manning) parameter. The model was calibrated with a particular interest for high flow conditions. In order to include a realistic opening of the Bonnet Carre Spillway stage a discharge and water level time series originating from 1997 was used for the calibration procedure. The discharge into the spillway is schematised as a lateral outflow that is the surplus of 


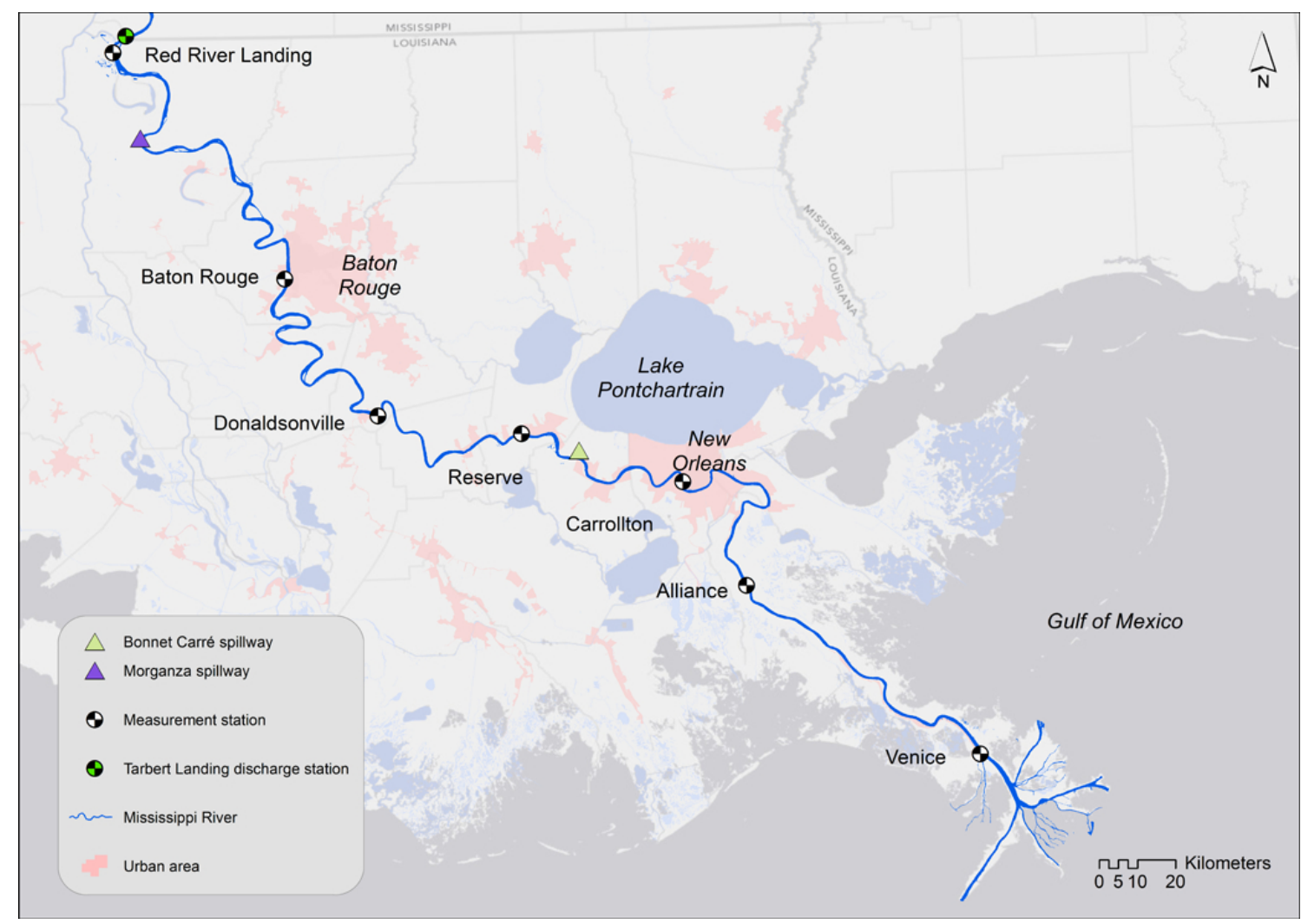

Figure 1. Map of the study area of the Mississippi River.

discharge relative to the discharge criterion of the spillway. Ten discharge bins were defined based on the minimum and maximum discharge of that year. Based on the frequency of days that features each bin a certain weighting factor was defined for the daily discharges in each bin, so that each bin had an equal weight (10\%) in the calculation of the statistical parameters. These weighting factors were higher for higher discharges, since their occurrence was lower. A multi-criteria procedure was used, since one parameter does not indicate every aspect of a time series. An optimal friction coefficient was expected by compromising between multiple calibration parameters, such as the Nash-Sutcliffe coefficient (Nash and Sutcliffe, 1970), the weighted linear regression coefficient, the weighted absolute error and the weighted root square error. For six different segments along the Mississippi River the Manning friction value in the main channel was calibrated based on the simulated stages.

\subsection{Validation}

After completing the calibration procedure a validation of the model needed to be performed by running the model for a different time period. Validation of the model was performed using the Mississippi River flood of 2011. In this year there was an exceptionally high discharge of $45845 \mathrm{~m}^{3} \mathrm{~s}^{-1}$ measured at Tarbert Landing (USACE, 2011) that required the opening of the Bonnet Carre and Morganza Spillway for several days. The validation run simulated stages for the time period 1 January to 14 June 2011.

\subsection{Climate change projections}

The climate change impact on the Mississippi river stages was investigated by using different scenarios of sea level rise and upstream discharges. Based on the projections and the practical application of sea level rise, four situations were used: no sea level rise, $+0.45 \mathrm{~m},+0.70 \mathrm{~m}$ and $+1.00 \mathrm{~m}$ sea level rise. These scenarios were within the limits of the appropriate USACE directive (USACE, 2009). A study from USGCRP (2000) describes the general effects of climate change to the American catchments. These effects are used to simulate potential changes in river discharges. Hence, four projections of the upstream discharges were formulated by shifting the discharge hydrograph by a factor $0.95,1.05,1.10$ and 1.15. Both the mean and standard deviation changed according to this factor. Three other projections were formulated by multiplying the difference to the mean with a factor 1.1, 1.2 and 1.3. Hereby, the stages above and below the mean were exaggerated. It did not affect the mean, but increased the standard deviation by the used factors. Tweaking the hydrograph in aforementioned way finally resulted in four sea level rise projections and eight upstream discharge 

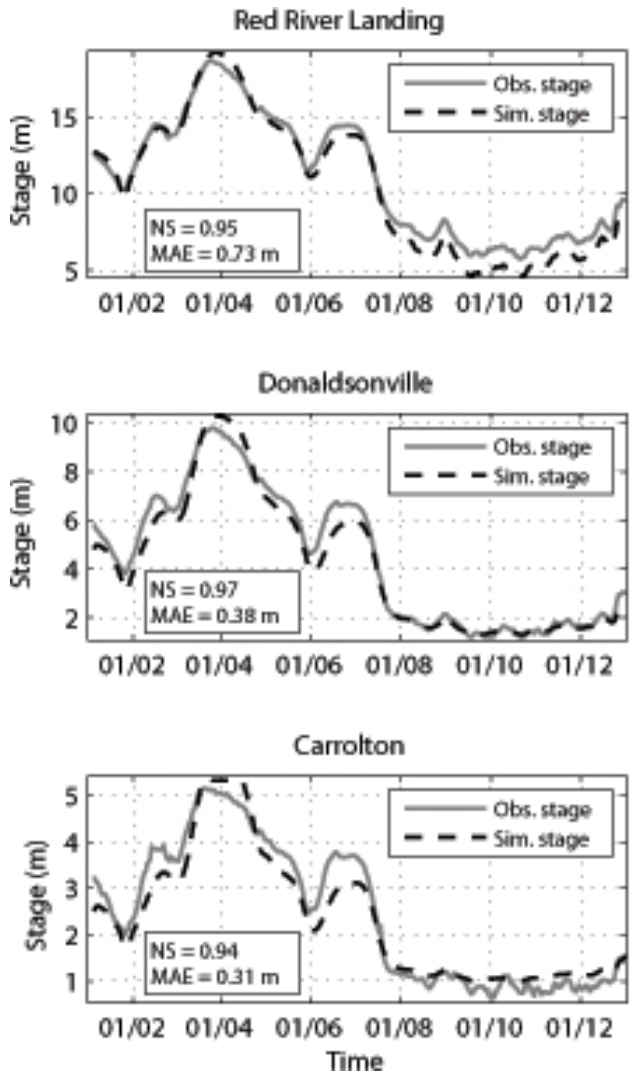

Figure 2. Hydrographs of calibrated simulation run 1997.

projections including the reference situations. Hence, 32 scenarios were used to assess the sensitivity of the Mississippi River stages to climate change. These scenarios are all under the assumption that there is an unchanged river bed.

\section{Results}

Figure 2 presents the results of the calibration procedure. The Nash-Sutcliffe coefficient and the mean absolute error are given for each location. The Nash-Sutcliffe coefficient assesses the predictive power of a hydrological model and its optimum value is 1 . It is calculated by one minus the residual variance divided by the data variance. The model results show an overestimation of the maximum discharge peak for all six measurement stations that were used. For the calibration period, the performance of the model to simulate water levels at Carrolton (New Orleans) is described with an 10th and 90th percentile of respectively $-0.6 \mathrm{~m}$ and $+0.3 \mathrm{~m}$. At Alliance, the model errors were relatively large and were partly caused by the tidal signal that was dominant at this location under low flow conditions. The error became relatively larger in downstream direction.

The validation results are given in Fig. 3 and show a good representation of the flood that occurred in May. Both the Bonnet Carre Spillway and the Morganza Spillway were
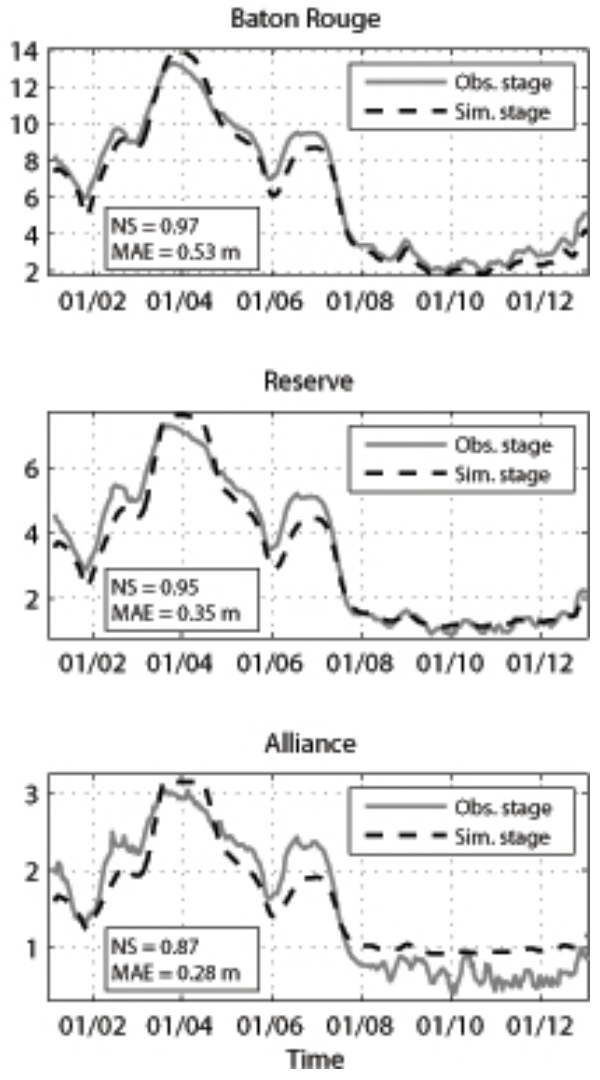

opened during this flood. The latter flooded an area as large as $7700 \mathrm{~km}^{2}$ and caused the displacement of ca. 25000 people. At Carrolton (New Orleans) the mean absolute error of the model simulation was $0.31 \mathrm{~m}$. At Red River Landing and Carrolton the difference of maximum stage was less than $0.01 \mathrm{~m}$, while at Baton Rouge the maximum stage was underestimated with $0.09 \mathrm{~m}$. At Alliance the maximum stage was overestimated with $0.25 \mathrm{~m}$. The simulated hydrographs had a shift with respect to the observed hydrographs, probably because the velocities in the model were underestimated. However, the model errors described above were relatively small considering the stage range of the Carrolton gage. Its average annual lowest and highest stages are respectively NAVD88 $-0.01 \mathrm{~m}$ and NAVD88 $+4.34 \mathrm{~m}$. The model demonstrated to be capable of simulating the hydrodynamics and, therefore, allowed a legitimate use of the model for a comparative analysis.

The model was also used to simulate the stages when the spillways would not have been opened (see Fig. 4). The impact on the stage at Carrolton (New Orleans) was especially of interest. The peak stage for this situation was projected to be NAVD88 $+7.17 \mathrm{~m}$, while the levee heights at Carrolton are ca. NAVD $88+7.30 \mathrm{~m}$. This clearly demonstrates the benefit that the spillways have in reducing flood hazard for the urban area of New Orleans. 

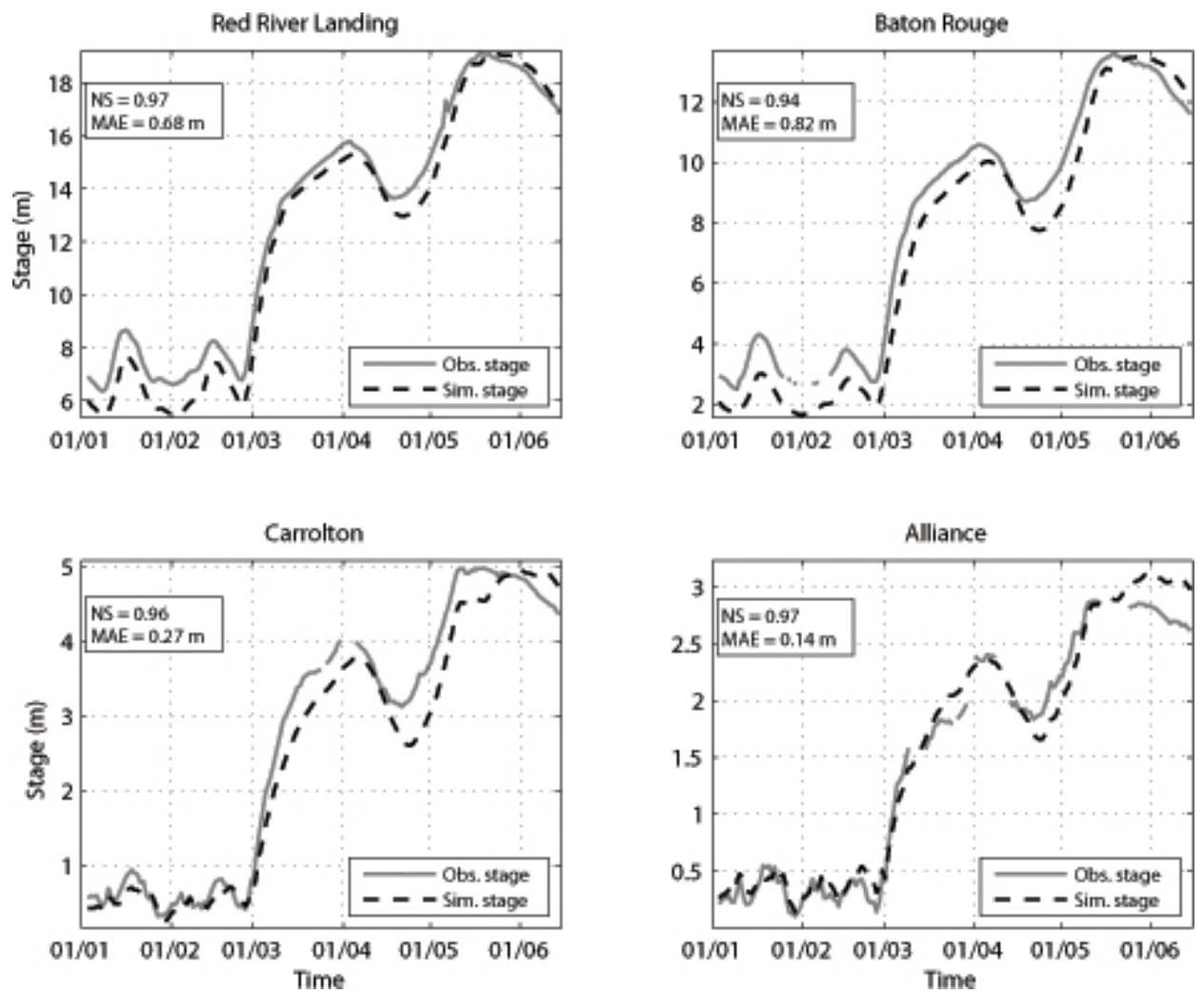

Figure 3. Validation of the flood in 2011.
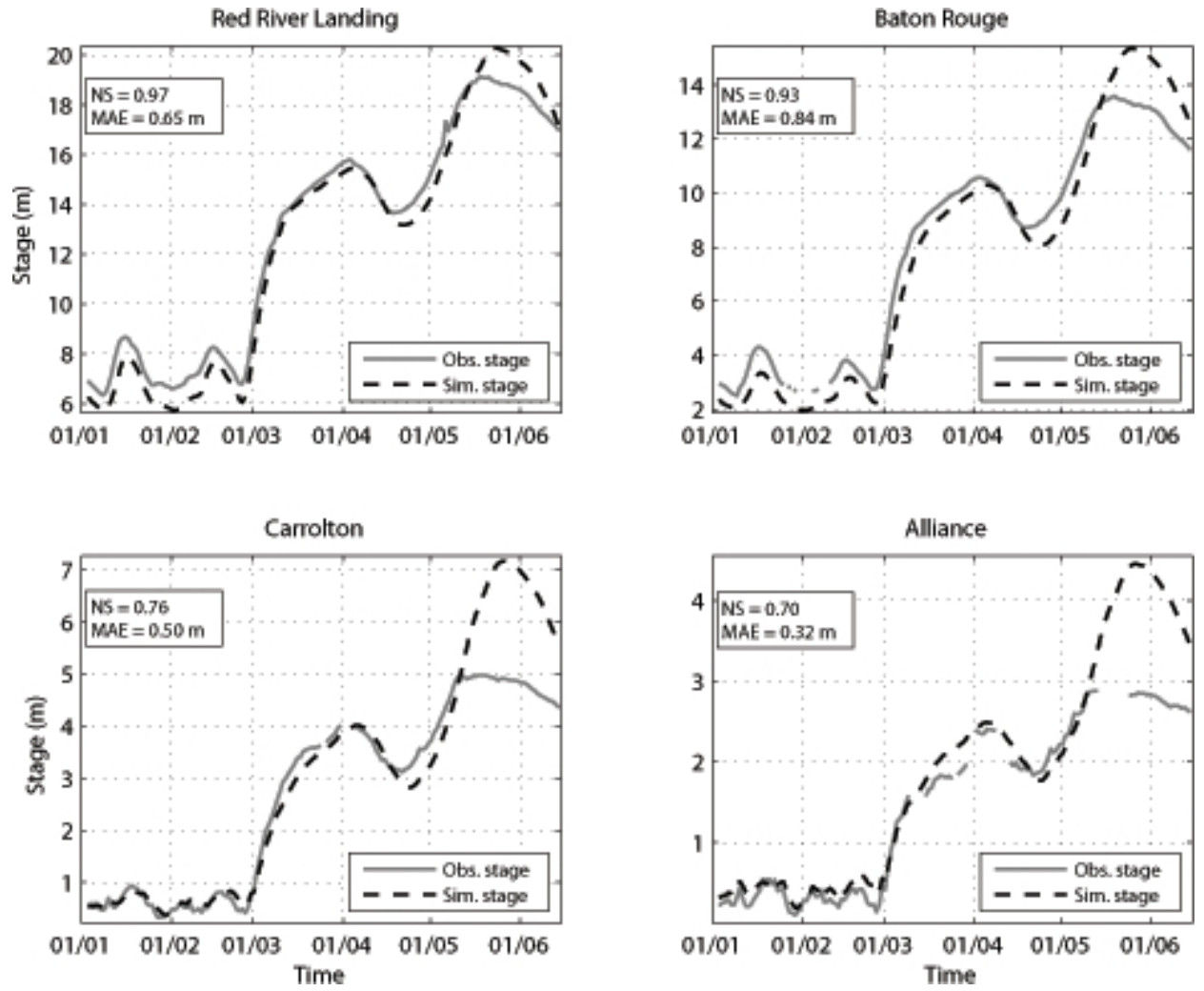

Figure 4. The validation of the flood in 2011 when no spillways are opened. 


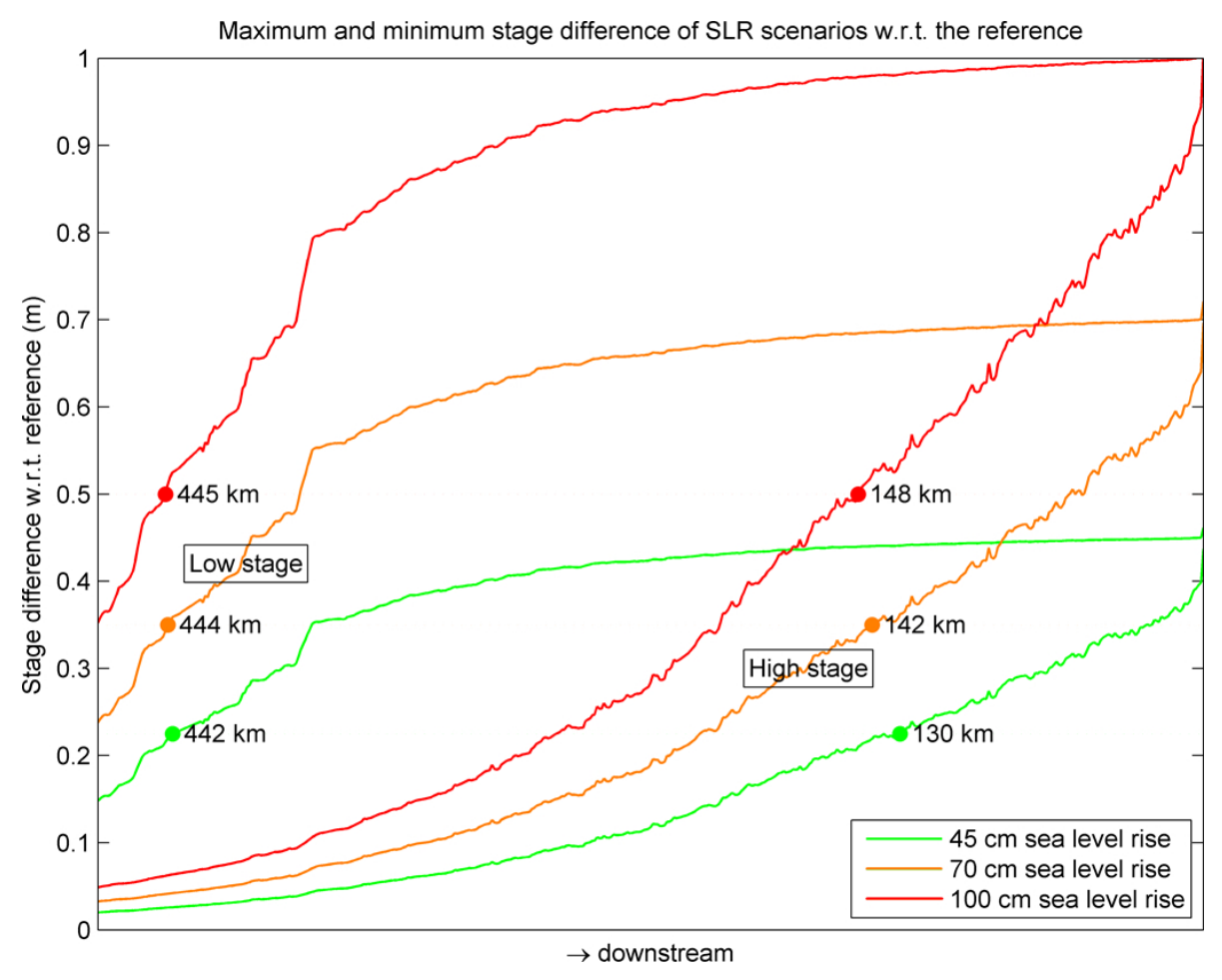

Figure 5. Minimum and maximum stage differences with respect to the reference for three sea level rise projections.

The defined scenarios were used to get an insight in the potential future behaviour of the Lower Mississippi system. By looking at the sea level rise scenarios where no discharge change is expected it can be concluded that the distance to the Gulf of Mexico, the position where the effect of sea level rise is halved, becomes larger with increasing sea level rise. The minimum stage difference with respect to the reference scenario occurs during high flow conditions when the stage is predominantly dependent on the discharge. Then, the sea level rise is halved at $130 \mathrm{~km}, 142 \mathrm{~km}$ and $148 \mathrm{~km}$ from the downstream boundary for respectively $+0.45 \mathrm{~m},+0.7 \mathrm{~m}$ and $+1.0 \mathrm{~m}$ sea level rise as can be seen in Fig. 5. The minimum increase of stage at Carrolton becomes $+0.21 \mathrm{~m},+0.34 \mathrm{~m}$ and $+0.50 \mathrm{~m}$ for all discharge regimes except the " $-5 \%$ "scenario. During low flow conditions the sea level affects the river stages stronger. In this case the sea level rise is halved at $442 \mathrm{~km}, 444 \mathrm{~km}$ and $445 \mathrm{~km}$ for respectively the same three sea level rise projections. It was found that the stages along the entire modelled reach are affected by sea level rise for the three projections. The maximum stage increase at Carrolton is dependent on the type of discharge regime as well as the strength of sea level rise.

The relative steep stage-discharge relation due to the confined levees downstream of Baton Rouge causes a strong increase in stages when upstream discharges increase. At the same time changes in discharge characteristics did not affect the stages downstream of Bonnet Carre Spillway when it was closed, since a constant discharge passed through. However, changes in the upstream discharge would affect the frequency and duration for opening of the spillways. Their effect on the water level near Carrolton is demonstrated in Figs. 3 and 4. The increase of stages in the downstream section is predominantly caused by the sea level rise. Currently, the threshold for a spillway opening is defined by the upstream discharge at Tarbert Landing. Sea level rise causes an increase in stage that changes the stage-discharge relationship. Thus in order to not exceed the NAVD88 $+5.18 \mathrm{~m}$ threshold at Carrolton it is likely that a lower discharge threshold is needed for opening the spillways.

\section{Conclusions}

The paper addressed the future changes in the Mississippi River stages regarding "climate change"-induced changes of upstream discharge and sea level. The weighted multi-criteria calibration procedure provided a hydrodynamic model that was capable of simulating high flows in the Mississippi River. During validation a mean absolute error at Carrolton (New Orleans) of $0.31 \mathrm{~m}$ was found and a difference during maximum stage that was less than $0.01 \mathrm{~m}$. It was concluded that the model could be used for a comparative analysis.

The presence of the two spillways proved to be of vital importance to reduce the flood hazard risk of the city New Orleans. In the future their role will even be more important. The challenges of the Mississippi River delta become even more apparent with expected climate change impacts. 
All of them increase the flood hazard in the Greater New Orleans area, which is already situated in a flood-prone area. This study showed that sea level rise is likely to be dominant on the downstream end of the Bonnet Carre Spillway. During high flow conditions the stages near New Orleans could be increase with a range between $0.21 \mathrm{~m}$ and $0.50 \mathrm{~m}$. At the same time the increased upstream discharge increases the frequency and duration of spillway openings.

Appropriate measures to face these future water management challenges and reduce the flood hazard are not discussed in this paper. Nevertheless, the Mississippi River model that is presented in this paper can be of added value in the analyses of these flood risk reduction measures. In that case it is recommended to update the bathymetry and include a morphological module to further enhance the model's performance.

Edited by: L. Rietveld

\section{References}

Barry, J.: Rising Tide - The Great Mississippi Flood of 1927 and How it Changed America, Simon \& Schuster, New York, 1998.

Bourne Jr., J. K.: Gone with the water, National Geographic Magazine, available at: http://ngm.nationalgeographic.com/ngm/0410/ feature5/ (last access: May 2009), 2004.

Deltares: Design and analysis tools - SOBEK suite, available at: http://www.deltaressystems.com/hydro/product/108282/ sobek-suite (last access: October 2011), 2010.
Ericson, J., Vörösmarty, C., Dingman, S., Ward, L., and Meybeck, M.: Effective sea-level rise and deltas - Causes of change and human dimension implications, Global Planet. Change, 50, 6382, 2006.

Nash, J. I. and Sutcliffe, I. V.: River flow forecasting through conceptual models: Part I - A discussion of principles, J. Hydrol., 10, 282-290, 1970.

Nicholls, R. J., Wong, P. P., Burkett, V. R., Codignotto, J. O., Hay, J. E., McLean, R. F., Ragoonaden, S., and Woodroffe, C. D.: Coastal systems and low-lying areas. Climate Change 2007: Impacts, Adaptation and Vulnerability. Contribution of Working Group II to the Fourth Assessment Report of the Intergovernmental Panel on Climate Change, Cambridge University Press, Cambridge, UK, 315-356, 2007.

NOAA: Sea Levels Online, available at: http://tidesandcurrents. noaa.gov/sltrends/sltrends.shtml, last access: 28 August 2011.

U.S. Army Corps of Engineers Washington: Water Resource Policies and Authorities Incorporating Sea-level Change Considerations in Civil Works Programs, available at: http://140.194.76. 129/publications/eng-circulars/ec1165-2-211/entire.pdf (last access: 28 August 2011), 2009.

U.S. Army Corps of Engineers: Discharge Data; Mississippi River at Tarbert Landing, MS, available at: http://www2.mvn.usace. army.mil/cgi-bin/wcmanual.pl?01100, last access: 11 October 2011.

USGCRP: Climate change impacts on the United States - The potential consequences of climate variability and change, US Global Change Research Program, 2000. 